\title{
EFEITO DA APLICAÇÃO DE CIANAMIDA HIDROGENADA E DE ÓLEO MINERAL EM CAQUIZEIRO ${ }^{1}$
}

\author{
GISELE POLETE MIZOBUTSI², CLÁUDIO HORST BRUCKNER³, LUIZ CARLOS CHAMHUM SALOMÃO , \\ ROSILENE ANTONIO RIBEIRO ${ }^{4}$, WAGNER FERREIRA da MOTTA ${ }^{4}$
}

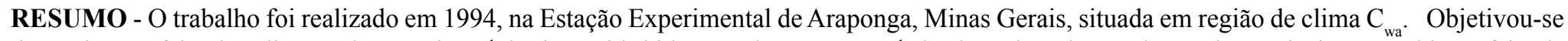
determinar o efeito da aplicação de 7,8 g. i.a.L $\mathrm{L}^{-1}$ de cianamida hidrogenada $+8,0 \mathrm{~mL} \cdot \mathrm{L}^{-1}$ de óleo mineral para plantas de caquizeiro cv. Rubi e o efeito de épocas de aplicações (9-6, 30-6, 21-7 e 11-8-1994). Todos os tratamentos com cianamida hidrogenada + óleo mineral anteciparam o início da brotação, do florescimento e da colheita em relação às plantas-testemunha, permitindo colheita precoce a partir de dezembro. O teor de sólidos solúveis, acidez titulável e frutificação efetiva foram maiores quando a aplicação de cianamida hidrogenada + óleo mineral foi realizada em 9-6. Não houve diferença significativa para a firmeza da polpa e a massa dos frutos.
\end{abstract}

Termos para indexação: Diospyros kaki L., quebra de dormência, antecipação da colheita

\section{EFFECT OF APPLICATION OF HYDROGEN CYANAMIDE PLUS MINERAL OIL ON PERSIMMON TREES}

\begin{abstract}
This study was conducted in 1994 at the Experiment Station of Araponga, Minas Gerais, located in a region of $\mathrm{C}_{\mathrm{wa}}-\mathrm{climate}^{-}$The objective was to determine the effect of application of 7,8 g. i.a. $\mathrm{L}^{-1}$ hydrogen cyanamide plus $8,0 \mathrm{~mL} \cdot \mathrm{L}^{-1}$ mineral oil on persimmon trees cv. Rubi, and the effect of application dates $(6 / 9,6 / 30,7 / 21,8 / 11 / 1994)$. All the treatments using hydrogen cyanamide plus mineral oil promoted earlier bud burst, flowering and harvesting compared to the control, permiting fruit harvesting begining in december. The content of soluble solids and titratable acidity and fruit set increased with the application of hydrogen cyanamide plus mineral oil in 6/9. There was no significant difference for flesh firmness and average fruit weight.
\end{abstract}

Index terms: Diospyros kaki L., breaking of dormancy, earlier harvesting.

\section{INTRODUÇÃO}

O caquizeiro (Diospyros kaki L.) é originário da Ásia, onde é cultivado há séculos, notadamente na China e no Japão (Andersen \& Pinheiro, 1974). No Brasil, foi introduzido no final do século passado através do Estado de São Paulo, que se destaca até hoje como maior produtor, sendo seguido pelo Rio Grande do Sul, Paraná, Rio de Janeiro e Minas Gerais (Anuário Estatístico do Brasil, 1997).

Fruteira de clima tipicamente subtropical, é uma boa opção para a fruticultura nacional, por apresentar excelente capacidade de adaptação às condições brasileiras, sendo altamente produtiva e rústica, requerendo poucos tratos culturais e adaptando-se aos mais variados tipos de solo (Andersen \& Pinheiro, 1974)

O caquizeiro é uma planta caducifólia, ou seja, perde as folhas e permanece em dormência no inverno, a exemplo das fruteiras de clima temperado (Ragazzini, 1985). Por tratar-se de uma planta de clima subtropical, seu cultivo em condições de pouco frio hibernal, tal como ocorre no Brasil e em outros países, se dá com a utilização de cultivares pouco exigentes em frio e com a quebra de dormência com produtos químicos (Arellano, 1991). Os produtos utilizados para a quebra de dormência, como o óleo mineral, cálcio cianamida $\left(\mathrm{CaCN}_{2}\right)$, nitrato de potássio $\left(\mathrm{KNO}_{3}\right)$, cianamida hidrogenada $\left(\mathrm{H}_{2} \mathrm{CN}_{2}\right)$ e paclobutrazol, podem uniformizar e antecipar a brotação e a floração em determinadas condições, como verificado em pessegueiro, pereira, videira e macieira (Arellano, 1991; Mann et al., 1994). Pesquisas realizadas demonstram que, dentre os produtos disponíveis no mercado, a cianamida hidrogenada é o mais eficiente produto químico para a quebra de dormência (George \& Nissen, 1988, 1993; George et al., 1992; Mann et al., 1994).

O modo de ação da cianamida hidrogenada como produto químico, para a quebra de dormência, não é ainda conhecido (George \& Nissen, 1993). Sabe-se, entretanto, que a cianamida hidrogenada é rapidamente absorvida e metabolizada (Goldback et al., 1988) e que causa diminuição da atividade da catalase, sem modificar a da peroxidase (Shulman et al., 1986), o que resulta num aumento da concentração de água oxigenada $\left(\mathrm{H}_{2} \mathrm{O}_{2}\right)$ nos tecidos das gemas. Este aumento, poderia ser responsável pela ativação do ciclo das pentoses e conseqüente indução da quebra de dormência das gemas (Omran, 1980). A cianamida hidrogenada induz a rápida mudança no conteúdo de glutationa reduzido (GSH), em gemas de pessegueiro (Siller-Cepeda et al., 1992). Uma diminuição do nível de GSH dentro de 12 horas após a aplicação de cianamida hidrogenada pode sugerir que GSH presente nos tecidos foi provavelmente utilizada na desintoxicação de água oxigenada gerada, quando a atividade da catalase foi inibida (Amberger, 1984)

Tendo em vista os efeitos positivos dos produtos químicos em substituir a ação das baixas temperaturas, uniformizar e antecipar a brotação e a floração, os objetivos deste trabalho foram estudar a eficiência da combinação de cianamida hidrogenada e óleo mineral em quebrar a dormência e antecipar a colheita a partir da antecipação da brotação, aumentando o período de oferta do caqui, que normalmente ocorre entre fevereiro e abril.

\section{MATERIAL E MÉTODOS}

O experimento foi instalado em 1994, na Estação Experimental de Araponga, Minas Gerais, situada em região de clima $\mathrm{C}_{\mathrm{wa}}$, segundo classificação de Köeppen, coordenadas geográficas de $20^{\circ} 40$ de latitude Sul e $42^{\circ} 31$ de longitude Oeste e 880 metros de altitude.

As plantas de caqui, cultivar rubi, foram pulverizadas com o produto comercial cianamida hidrogenada (Dormex), ao qual foi acrescentado óleo mineral. A aplicação foi feita por meio da pulverização completa da planta, com pulverizador acoplado ao trator, equipado com pistola, e o volume utilizado foi aproximadamente de 10 litros por planta. A aplicação ocorreu quando as plantas estavam dormentes, ou seja, durante o estádio fenológico A (Baggiolini, 1952).

O delineamento foi inteiramente ao acaso, com uma planta por parcela e bordadura. Os tratamentos foram constituídos de quatro épocas de aplicações, realizadas em 9-6, 30-6, 21-7 e 11-8-1994, mais as plantas-testemunha, que não receberam nenhuma aplicação. A dose utilizada foi 7,8 g. i.a. $\mathrm{L}^{-1}$ de cianamida hidrogenada acrescido de 8,0

\footnotetext{
1 (Trabalho 023/2003). Recebido: 08/01/2003. Aceito para publicação: 09/04/2003.

${ }^{2}$ Eng. Agr., M.S. Fitotecnia, Universidade Federal de Viçosa, Viçosa-MG, CEP 36571-000. e-mail: gpolete@alunos.ufv.br.

${ }^{3}$ Eng. Agr., Dr., Dep. de Fitotecnia, Universidade Federal de Viçosa, Viçosa-MG, CEP 36571-000. E-Mail: bruckner@mail.ufv.br e 1salomao@mail.ufv.br.

${ }^{4}$ Eng.Agr., Estudante de Doutorado Fitotecnia, Universidade Federal de Viçosa, Viçosa-MG, CEP 36571-000.
} 
mL. $\mathrm{L}^{-1}$ de óleo mineral, com quatro repetições. O espaçamento entre plantas foi de 6 × 6 metros.

Os frutos foram amostrados quando foi observada a mudança da coloração verde para amarelo-avermelhada.

Foram avaliadas as datas da brotação, do florescimento e da colheita, a fixação, a massa, a firmeza da polpa, o teor de sólidos solúveis e a acidez titulável dos frutos. A partir das datas da brotação, florescimento e colheita, calculou-se a antecipação em relação às respectivas datas da testemunhas.

O critério adotado para caracterizar-se o início da brotação e do florescimento foi quando $50 \%$ das gemas se encontravam nos estádios fenológicos C e F, respectivamente (Baggiolini, 1952). As anotações foram efetuadas com intervalos de sete dias. A massa dos frutos foi obtida de vinte frutos, e cinco desses foram usados para avaliar a firmeza da polpa, a acidez titulável e o teor de sólidos solúveis. A acidez titulável foi determinada por titulometria (A.O.A.C., 1975). O teor de sólidos solúveis foi determinado por refratometria, seguindo o método descrito por Sugiura et al. (1983). A firmeza da polpa foi determinada por meio do penetrômetro MAGNESS-TAYLOR, com ponta de 5/32, onde os frutos foram avaliados em três locais na região equatorial, após a retirada da casca do local. Obteve-se a frutificação efetiva a partir de cálculo percentual do número de frutos no estádio de máximo crescimento sobre o de flores, ambos existentes em cinco ramos escolhidos ao acaso nas plantas de cada tratamento.

A análise estatística foi realizada, utilizando-se o Sistema de Análise Estatística e Experimental - SAEG (Euclides, 1983). Os dados foram ajustados através da análise de regressão, com base na significância dos parâmetros linear e quadrático.

\section{RESULTADOS E DISCUSSÃO}

A análise de regressão indica comportamento linear decrescente, para o período entre a aplicação da cianamida hidrogenada e a brotação em relação às plantas não pulverizadas, com a época de aplicação (Figura 1), alcançando 10,5 semanas de antecipação quando a aplicação foi realizada em 9-6. A partir desses resultados, pode-se confirmar o efeito da cianamida hidrogenada na quebra de dormência e na uniformização da brotação e floração, como relatado por Walton \& Fowke (1993) em plantas de kiwi. A cianamida hidrogenada + óleo mineral produziram antecipação da brotação quando comparado com as plantas não pulverizadas; as primeiras brotações desses tratamentos podem estar relacionadas com a superação precoce da dormência, devido a vários fatores, como o balanço das substâncias inibidoras e promotoras de crescimento, resultante da ação da cianamida hidrogenada, que promove a ativação da rota das pentoses, levando à quebra de dormência das gemas. Pires (1991), avaliando o efeito de agentes químicos na indução da brotação, no desenvolvimento dos ramos e na produção da videira cv. Niagara Rosada, verificou que os tratamentos com cianamida hidrogenada, independentemente das doses aplicadas, quebraram a dormência das gemas e anteciparam o desenvolvimento vegetativo em vinte e um dias.

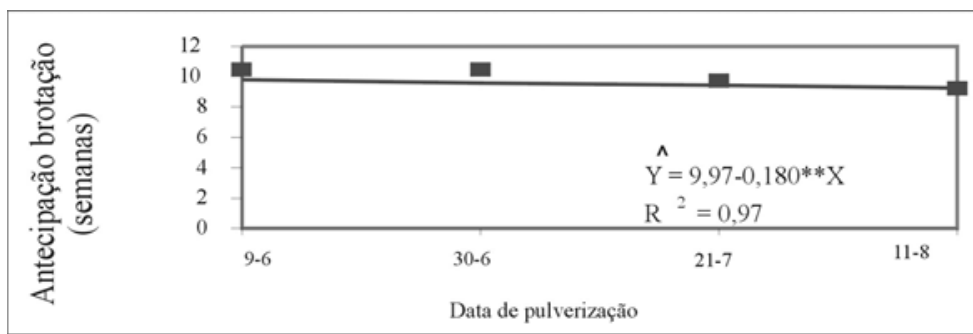

FIGURA 1- Antecipação da brotação de caquizeiro ‘Rubi' submetido à aplicação da cianamida hidrogenada e óleo mineral em relação às plantas não pulverizadas.

Houve tendência de decréscimo linear para o período entre a aplicação da cianamida hidrogenada e o florescimento em relação às plantas não pulverizadas, com a época de aplicação (Figura 2), alcançando 11,25 semanas de antecipação quando a aplicação foi realizada em 96 (Tabela 1). Mann et al. (1994) verificaram que peras 'Baggugosha', tratadas com cianamida hidrogenada a 20,30 e $40 \mathrm{~mL} . \mathrm{L}^{-1}$ do produto comercial, tiveram o florescimento antecipado em dez dias, e George \& Nissen (1993) obtiveram dez dias de antecipação para o florescimento de pessegueiro cultivar Flordaprince, pulverizando-os com $5 \mathrm{~mL} . \mathrm{L}^{-1} \mathrm{de}$ cianamida hidrogenada. Com relação aos resultados obtidos, pode-se relatar que, como a cianamida hidrogenada compensa a falta de horas de frio necessárias para que a dormência seja rompida e proporciona rápida quebra de dormência das gemas vegetativas, permite também que haja antecipação do florescimento (George \& Nissen, 1993; Petri, 1987; Petri \& Stuker, 1995) e, como citado por Walton et al. (1991), a cianamida hidrogenada causa aumento na concentração do aminoácido prolina nas gemas das plantas tratadas, que pode favorecer o florescimento precoce.

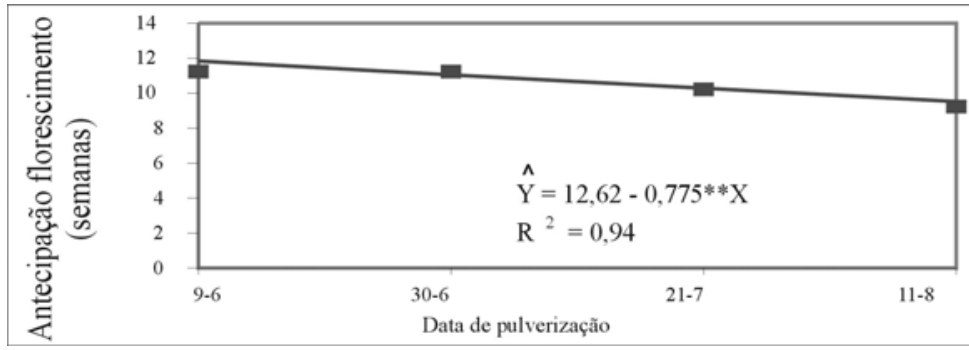

FIGURA 2- Antecipação do florescimento de caquizeiro 'Rubi' submetido à aplicação de cianamida hidrogenada e óleo mineral em relação às plantas não pulverizadas.

TABELA 1- Período entre a aplicação da cianamida hidrogenada e a brotação, o florescimento e a colheita dos tratamentos.

\begin{tabular}{|c|c|c|c|c|c|c|c|c|c|}
\hline \multirow[t]{2}{*}{ Data da aplicaçã } & \multicolumn{3}{|c|}{ BROTAÇÃO } & \multicolumn{3}{|c|}{ FLORESCIMENTO } & \multicolumn{3}{|c|}{ COLHEITA } \\
\hline & Data & $\begin{array}{c}\text { Média dos dias } \\
\text { após a a } \\
\text { plicação }\end{array}$ & $\begin{array}{c}\text { Antecipação } \\
\text { média em relação } \\
\text { à testemunha } \\
\text { (semana) }\end{array}$ & Data & $\begin{array}{l}\text { Média dos } \\
\text { dias após a } \\
\text { aplicação }\end{array}$ & $\begin{array}{c}\text { Antecipação média } \\
\text { em relação à } \\
\text { testemunha } \\
\text { (semana) }\end{array}$ & Data & $\begin{array}{l}\text { Média dos } \\
\text { dias após a } \\
\text { aplicação }\end{array}$ & $\begin{array}{c}\text { Antecipação média } \\
\text { em relação à } \\
\text { testemunha } \\
\text { (semana) }\end{array}$ \\
\hline $9-6$ & $3-7$ & 24,5 & 10,5 & $22-7$ & 43,75 & 11,25 & $2-12$ & 176,75 & 11,75 \\
\hline $30-6$ & $24-7$ & 24,5 & 10,5 & $13-8$ & 43,75 & 11,25 & $30-12$ & 182,00 & 11,0 \\
\hline $21-7$ & $18-8$ & 28,0 & 9,75 & $10-9$ & 50,75 & 10,25 & $1^{o}-2$ & 194,25 & 9,0 \\
\hline $11-8$ & $12-9$ & 31,5 & 9,25 & $8-10$ & 57,75 & 9,25 & $13-3$ & 213,50 & 6,25 \\
\hline Testemunha & $15-9$ & 96,25 & 0 & $11-10$ & 122,50 & 0 & $27-2$ & 257,25 & 0 \\
\hline $\mathrm{F}$ & & $217,97^{*}$ & & & $149,87^{*}$ & & & $165,56^{*}$ & \\
\hline C.V. $(\%)$ & & 10,44 & & & 8,67 & & & 2,50 & \\
\hline
\end{tabular}

(1) Período da colheita de cada tratamento é contado a partir da $1^{\mathrm{a}}$ aplicação, realizada em 9-6.

*significativo a $1 \%$ de probabilidade. 
A análise de regressão mostra o comportamento linear decrescente, para o período entre a aplicação da cianamida hidrogenada e a colheita em relação às plantas não pulverizadas, com a época de aplicação (Figura 3), alcançando 11,50 semanas de antecipação quando a aplicação foi realizada em 9-6. A colheita ocorreu a partir da segunda quinzena de dezembro até final de fevereiro para as plantas pulverizadas, e em março para as plantas não pulverizadas, antecipando a colheita em dois meses e meio. O resultado obtido foi muito satisfatório, pois a colheita coincidiu com a época em que a oferta de caqui é mais baixa e conseqüentemente o preço é menor. O início precoce da colheita e sua antecipação em relação às plantas não pulverizadas foi devido à eficiência da cianamida hidrogenada e do óleo mineral em quebrar a dormência, antecipar a brotação e o florescimento, e isso pode ser verificado no trabalho realizado por Pires et al. (1995), em que a colheita de uva 'Itália' foi antecipada em 20 dias, com a aplicação de cianamida hidrogenada. É fundamental verificar que o efeito da cianamida hidrogenada, varia em função de vários fatores, como concentração, época, modo de aplicação, espécie, cultivar e condições climáticas.

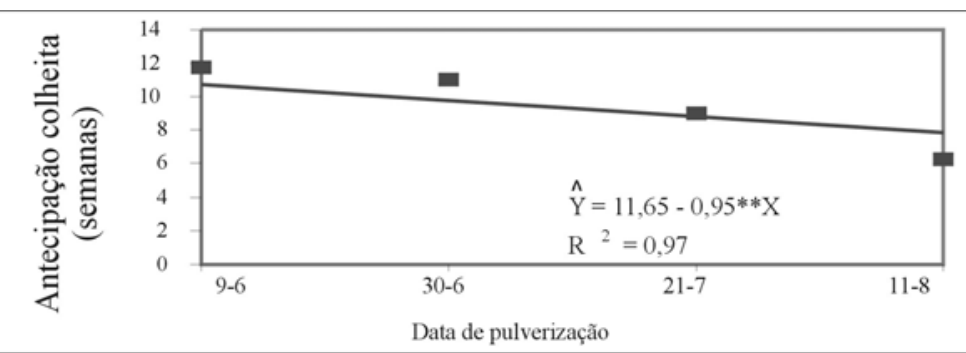

FIGURA 3- Antecipação da colheita de caquizeiro 'Rubi' submetido à aplicação de cianamida hidrogenada e óleo mineral em relação às plantas não pulverizadas.

Observou-se tendência linear decrescente para a frutificação efetiva, com a época de aplicação (Figura 4) alcançando o valor máximo de 92,5\%, quando a aplicação foi realizada em 9-6 (Tabela 2). Os valores médios obtidos assemelham-se, em parte, aos resultados obtidos por Miele (1991), onde a pulverização de cianamida hidrogenada por ocasião da poda seca, nas concentrações de $0 ; 10 ; 30$ e $50 \mathrm{~mL} . \mathrm{L}^{-1}$ do produto comercial, causou efeito altamente significativo sobre o número de cachos de uva por planta. Porém, os valores diferem dos resultados encontrados por George et al. (1992), onde a cianamida hidrogenada, aplicada a $20 \mathrm{~mL} . \mathrm{L}^{-1}$ do produto comercial em pessegueiro cultivar Flordaprince, reduziu a frutificação efetiva. A aplicação de cianamida hidrogenada e óleo mineral pode ter aumentado a aderência dos frutos ao pedúnculo, por estabelecer alta taxa de atividade metabólica no ovário, resultando na fluência de metabólitos para os frutos e reduzindo a queda (George \& Nissen, 1993), o que também foi verificado no trabalho realizado por Schuck \& Petri (1995), em que a cianamida hidrogenada causou efeito altamente significativo na fixação dos frutos de kiwi.

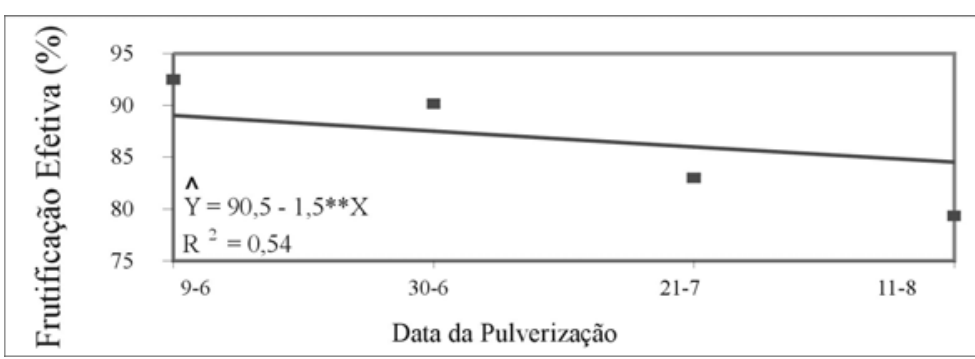

FIGURA 4- Frutificação efetiva de caquizeiro 'Rubi' submetido à aplicação de cianamida hidrogenada em relação às plantas não pulverizadas.

A análise de regressão indica o comportamento linear decrescente, para o teor de sólidos solúveis, com a época de aplicação (Figura 5) alcançando o maior teor de sólidos solúveis (15,2\%) quando a aplicação foi realizada em 9-6, e o menor quando a aplicação foi realiza- da em 11-8 (13,65\%), (Tabela 2). As diferenças podem ser consideradas insignificantes para afetar a qualidade do caqui.

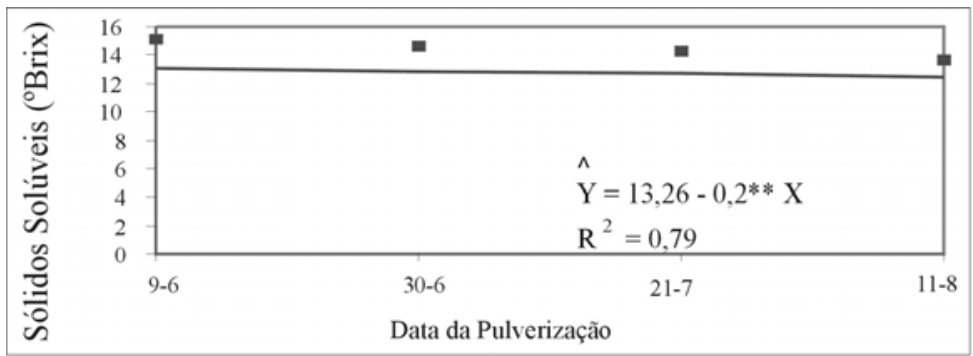

FIGURA 5- Teor de sólidos solúveis de caquizeiro 'Rubi' submetido à aplicação de cianamida hidrogenada em relação às plantas não pulverizadas.

TABELA 2- Valores médios de fixação dos frutos, sólidos solúveis totais, acidez titulável, firmeza da polpa e massa dos frutos.

\begin{tabular}{|c|c|c|c|c|c|}
\hline $\begin{array}{l}\text { Data da } \\
\text { aplicação }\end{array}$ & $\begin{array}{l}\text { Fixação dos } \\
\text { frutos }\end{array}$ & $\begin{array}{r}\text { S Sólidos } \\
\text { solúveis }\end{array}$ & $\begin{array}{c}\text { Firmeza da } \\
\text { polpa }\end{array}$ & $\begin{array}{c}\text { Massa } \\
\text { dos frutos }\end{array}$ & $\begin{array}{c}\text { Acidez } \\
\text { titulável }\end{array}$ \\
\hline & $(\%)$ & ( ${ }^{\circ}$ Brix) & $(\mathrm{N})$ & (g) & $\begin{array}{c}\text { g.eq.acido } \\
\text { citrico/ } / 100 \mathrm{~mL} \text { succ }\end{array}$ \\
\hline $9-6$ & 92,50 & 15,20 & 39,79 & 133,15 & 0,23 \\
\hline $30-6$ & 90,17 & 14,65 & 37,75 & 132,19 & 0,21 \\
\hline $21-7$ & 83,00 & 14,35 & 39,85 & 133,05 & 0,19 \\
\hline $11-8$ & 79,35 & 13,65 & 38,11 & 131,12 & 0,16 \\
\hline Testemunha & 85,74 & 13,23 & 38,52 & 132,42 & 0,17 \\
\hline $\mathrm{F}$ & $16,34^{\prime \prime}$ & 3,98 & $0,16^{\text {n.s. }}$ & $0,70^{\text {n.s. }}$ & $17,03^{2 n}$ \\
\hline C.V. $(\%)$ & 2,19 & 4,97 & 8,16 & 6,08 & 4,93 \\
\hline
\end{tabular}

**, significativo a $1 \%$ de probabilidade. n.s. , não significativo.

Observou-se tendência de redução linear para a acidez titulável, com a época de aplicação (Figura 6) alcançando a menor acidez titulável 0,16 g.eq. ácido cítrico/ $100 \mathrm{~mL}$ suco quando a aplicação foi realizada em 11-8 (Tabela 2). A acidez titulável apresentou comportamento diferenciado, onde os frutos que apresentaram maior acidez foram os pulverizados na primeira época de aplicação, não comprometendo a qualidade dos demais frutos, devido à pequena variação entre as demais épocas de aplicações. Os resultados obtidos estão de acordo com os encontrados por Fonseca (1973), que classificou o caqui como pobre em acidez, e Costa (1984), que verificou que o nível de acidez variou da ordem de $0,16 \%$ a $0,28 \%$ para seis variedades. Estes resultados, em parte, assemelham-se aos encontrados por Mann et al. (1994), onde verificaram um correspondente decréscimo na acidez de frutos de pêra 'Baggugosha' pulverizadas com cianamida hidrogenada.

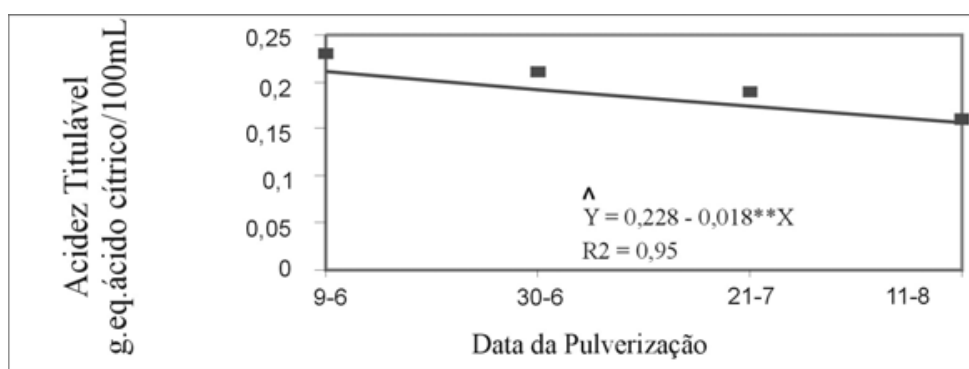

FIGURA 6- Acidez titulável de caquizeiro ‘Rubi’ submetido à aplicação de cianamida hidrogenada em relação às plantas não pulverizadas.

A firmeza da polpa e a massa dos frutos não foram influenciadas pela aplicação de cianamida hidrogenada + óleo mineral e épocas de aplicação dos produtos, atingindo valores médios de 38,88N e 132,37 g, respectivamente.

\section{CONCLUSÕES}

1) A cianamida hidrogenada + óleo mineral quebram a dormência 
e antecipam a brotação, o florescimento e a colheita no caquizeiro variedade Rubi.

2) O teor de sólidos solúveis e a acidez titulável são maiores para a aplicação realizada em 9-6.

3) Cianamida hidrogenada + óleo mineral não alteraram a firmeza da polpa, nem a massa dos frutos de caquizeiro cv. Rubi.

\section{REFERÊNCIAS BIBLIOGRÁFICAS}

AMBERGER, A. Uptake and metabolism of hydrogen cyanamide in plants. In: Bud Dormancy of Grapevines. POTENTIALAND PRACTICALUSES OF HYDROGENCYANAMIDEONGRAPEVINES, 1984, Davis. Proceeding... Davis: University of California, 1984. p.5-10.

ANDERSEN, O., PINHEIRO, R.V. R. O caqui e sua cultura. Viçosa: UFV, 1974. 22p. (Série Técnica. Boletim, 47)

ANUÁRIO ESTATÍSTICO DO BRASIL. Rio de Janeiro, IBGE, 1997

ARELLANO, L.S. Uso de cianamida hidrogenada em plantas de folhas caducas no Chile. In: WORSHOP-DORMEX, 1991, Vitória. Resumos... Vitória: BASF/SKW, 1991. 15p.

ASSOCIATION OF OFFICIALAGRICULTURAL CHEMISTS -A.O.A.C Official Methods of Analyses of the Association of Official Analytical Chemistry. 12 ed. Washington, 1975. 1094p.

BAGGIOLINI, M. Les stades repères dans le developpement annuel de la vigne. Revue Romande d'Arboriculture, v.8, p.4-6, 1952

COSTA, A. N. Produção e qualidade dos frutos de diferentes variedades de caqui (Diospyros kaki L.) visando à industrialização. Viçosa-MG: UFV, 1984. 50p. Dissertação (Mestrado em Fitotecnia) - Universidade Federal de Viçosa, 1984.

EUCLIDES, R.F. Sistema para análise estatística genética: SAEG. Viçosa-MG:UFV, 1983, 57p.

FONSECA, H. As frutas para geléias. Revista Brasileira de Bebidas e Alimentos, v.6, n.73, p.18-19, 1973.

GEORGE, A.P., NISSEN, R.J. Chemical methods of breaking dormancy of low chell nectarines: preliminary evaluations in subtropical Queensland. Australian Journal of Experimental Agriculture, v.28, p.425-429, 1988.

GEORGE, A. P., LLOYD, J., NISSEN, R.J. Effects of hydrogen cyanamide, paclobutrazol and pruning date on dormancy release of the chill peach cultivar Flordaprince in subtropical Australia. Australian Journal of Experimental Agriculture, v.32, p.89-95, 1992.

GEORGE, A. P., NISSEN, R. J. Effects of growth regulants on defoliation, flowering, and fruit maturity of the low chill peach cultivar Flordaprince in subtropical Australia. Australian Journal of Experimental Agriculture, v.33, p.787-795, 1993.
GOLDBACK, H., THALER, C., WÜNSCH, A., ET AL. Decomposition of 14C- labelled cyanamide in Vitis vinifera cuttings. Journal of Plant Physiology, v.133, p.299-303, 1988.

MANN, S., SINGH, H., SANDU, A. S., GREWAL, G. P. S. Effect of cyanamide on bud burst, flowering and fruit maturity of Baggugosha pear. Acta Horticulturae, v.367, p.214-223, 1994.

MIELE, A. Efeito da cianamida hidrogenada na quebra de dormência das gemas, produtividade do vinhedo e composição química do mosto da uva Cabernet sauvignon. Pesquisa Agropecuária Brasileira, v.26, n.3, p.315-324, 1991.

OMRAN, R.G. Peroxide levels and the activities of catalase, peroxidase, and indoleacetic acid oxidase during and after chilling of cucumber seedlings. Plant Physiology, v.65, p. $407-408,1980$.

PETRI, J.L. Breaking dormancy of apple trees with chemicals. Acta Horticulturae, v. 199, p. 109-124, 1987.

PETRI, J.L., STUKER, H. Effect of mineral oil and hydrogen cyanamide concentrations on apple dormancy, cv. Gala. Acta Horticulturae, v.395, p. 169-176, 1995.

PIRES, E. J. P. Efeito de agentes químicos na indução da brotação, desenvolvimento dos ramos e na produção da videira-cv. Niagara Rosada. In: WORKSHOP. Dormex. BASF / SKW. Vitória, 1991.26p.

PIRES, E. J. P., TERRA, M. M., POMMER, C.V. Adjustment of ideal $\mathrm{H}_{2} \mathrm{CN}_{2}$ concentration for breaking dormancy of grapevine in less warn region. Acta Horticulturae, v.395, p.169-176, 1995.

RAGAZZINI, D. El kaki. Madri: Ediciones Mundi-prensa, 1985. 176p.

SCHUCK, E., PETRI, J.L. The effect of concentrations and application of hydrogen cyanamide on kiwifruit dormancy breaking. Acta Horticulturae, v.395, p. 177-183, 1995.

SUGIURA, A., KATAOKA, I., TOMANA, T. Use of refractometer to determine soluble solids of astringenct fruits of japanese persimmon (Diospyros kaki L.). Journal of Horticultural Science, v.58, n.2, p.241-246, 1983

SHULMAN, Y., NIR, G., LAVEE, S. Oxidative processes in bud dormancy and the use of hydrogen cyanamide in breaking dormancy. Acta Horticulturae, v.179, p. 141-48, 1986.

SILLER-CEPEDA, J.H., FUCHIGAMI, L.H., CHEN, T.H.H. Glutathione content in peach buds in relation to development and release of rest. NPlant Cell Physiology, v.33, n.7, p.867-872, 1992.

WALTON, E. F., CLARK, C. J., BOLDINGH, H. L. Effect of hydrogen cyanamide on amino acid profiles in kiwifruit buds during budbreak. Plant Physiology, v.97, p.1256-59, 1991.

WALTON, E. F., FOWKE, P.J. Effect of hydrogen cyanamide on kiwifruit shoot flower number and position. Journal of Horticultural Science, v.68, n.4, p.529-534. 1993. 